\title{
ЭЛЕМЕНТНЫЙ СОСТАВ ЛУГОВИКА ИЗВИЛИСТОГО В ФОНОВЫХ И АНТРОПОГЕННО ЗАГРЯЗНЕННЫХ РАЙОНАХ МУРМАНСКОЙ ОБЛАСТИ
}

\section{Сухарева T.A.}

Институт проблем промышленной экологии Севера КНЦ РАН, Anaтuты, s.tat.a@mail.ru

В напочвенном покрове северо-таежных лесов наряду с кустарничками, зелеными мхами и лишайниками нередко встречается луговик извилистый (Avenella flexuosa (L.) Drejer.). Это многолетнее травянистое растение, жизненная форма которого изменяется в процессе онтогенеза от плотно- к рыхлодерновинной с надземными столонами, формирующимися обычно во взрослом состоянии [1]. Предположительно мог возникнуть в доледниковую эпоху, и обитать в ранних постледниковых хвойных и березовых лесах [10]. На северных пастбищах является ценным зимним кормом для оленей, более богат протеином и сахарами, чем лишайники [3]. Известно, что растительный покров северотаежных лесов подвержен разнообразным внешним воздействиям, в том числе аэротехногенному воздействию. В таких условиях трансформируется химический состав наземных вегетативных органов растений, выражающийся в потери биофильных элементов и накоплении поллютантов. Сведения об элементном составе луговика извилистого в литературе немногочисленны $[5,6]$, хотя данный вид является устойчивым компонентом растительных сообществ в условиях техногенного загрязнения.

Целью данного исследования явилась оценка химического состава листьев луговика извилистого в условиях воздействия металлургических предприятий предприятия АО «Кольская ГМК».

Объект исследования - луговик извилистый (Avenella flexuosa (L.) Drejer.), произрастающий в северо-таежной подзоне ельников кустарничково-зеленомошных и сосняков лишайниковокустарничковых, функционирующих на иллювиально-гумусовых подзолах. Исследования проводили в 2012-2013 г. в центральной, юго-западной и северо-западной части Мурманской области на сети постоянных пробных площадей (ПП) Института проблем промышленной экологии Севера ФИЦ КНЦ РАН в ненарушенных экосистемах и в зонах воздействия металлургических предприятий Мурманской области. ПП представляют основные стадии дигрессионной сукцессии северотаежных лесов [4]. Обследовано 8 ПП, расположенных по градиенту промышленного загрязнения от комбинатов «Североникель» $(7,31,62$ км) и «Печенганикель $(5,7,14,44$ км). Экосистемы, подверженные воздушному загрязнению, представлены дефолиирующими лесами (20-100 км от источника загрязнения) и техногенными редколесьями (5-20 км). Фоновые ПП расположены на значительном расстоянии от источника атмосферных выбросов, в юго-западной части Мурманской области. Ассимилирующие органы луговика отбирали в конце периода вегетации (август) в подкроновых и межкроновых пространствах в 5-кратной повторности. В зоне воздействия комбината «Печенганикель» пробы объединены в смешанный образец. Металлы (Ca, $\mathrm{Mg}, \mathrm{K}, \mathrm{Fe}, \mathrm{Mn}, \mathrm{Cu}, \mathrm{Ni}, \mathrm{Zn}$,) определяли методом атомно-абсорбционной спектрофотометрии, $\mathrm{K}$ - атомно-эмиссионной спектрометрии; $\mathrm{P}$ - фотоколориметрическим методом по интенсивности окраски фосфорно-молибденового комплекса (метод Лоури-Лопеса); S - турбидиметрическим методом, $\mathrm{N}$ - по методу Къельдаля, C - по методу Тюрина.

Установлено, что луговик извилистый отличается сравнительно высокой зольностью 3.0-3.5 \% на сухое вещество [5]. В таблице 1 приведены данные по содержанию макро- и микроэлементов в ассимилирующих органах луговика. Из минеральных элементов в луговике преобладают калий, азот и фосфор, ряд накопления имеет следующий вид: $\mathrm{K}>\mathrm{N}>\mathrm{P}>\mathrm{Ca}>\mathrm{S}>\mathrm{Mg}>\mathrm{Mn}>\mathrm{Fe}>\mathrm{Al}>\mathrm{Zn}>\mathrm{Ni}>\mathrm{Cu}$. Таким образом, луговик определяет азотно-калиевый тип биогеохимического круговорота. Фоновое содержание углерода в луговике составляет 41-51\%. В условиях загрязнения содержание углерода остается в пределах фоновых значений, хотя в отдельных случаях может достигать 53-57 \%.

Фоновая концентрация Ni в луговике варьирует в широких пределах, изменяясь от 2.3 до 5.8 мг кг ${ }^{-1}$. Диапазон изменения содержания Сu у́же и составляет от 3.4 до 4.1 мг кг $\Gamma^{-1}$ В условиях атмосферного загрязнения луговик накапливает тяжёлые металлы $(\mathrm{Cu}, \mathrm{Ni})$, превышающие фоновые концентрации в 1.2-3 раза на стадии дефолиирующих лесов и в 7-10 раз - вблизи источников атмосферных выбросов (стадия техногенного редколесья). Никель аккумулируется в луговике более ин- 


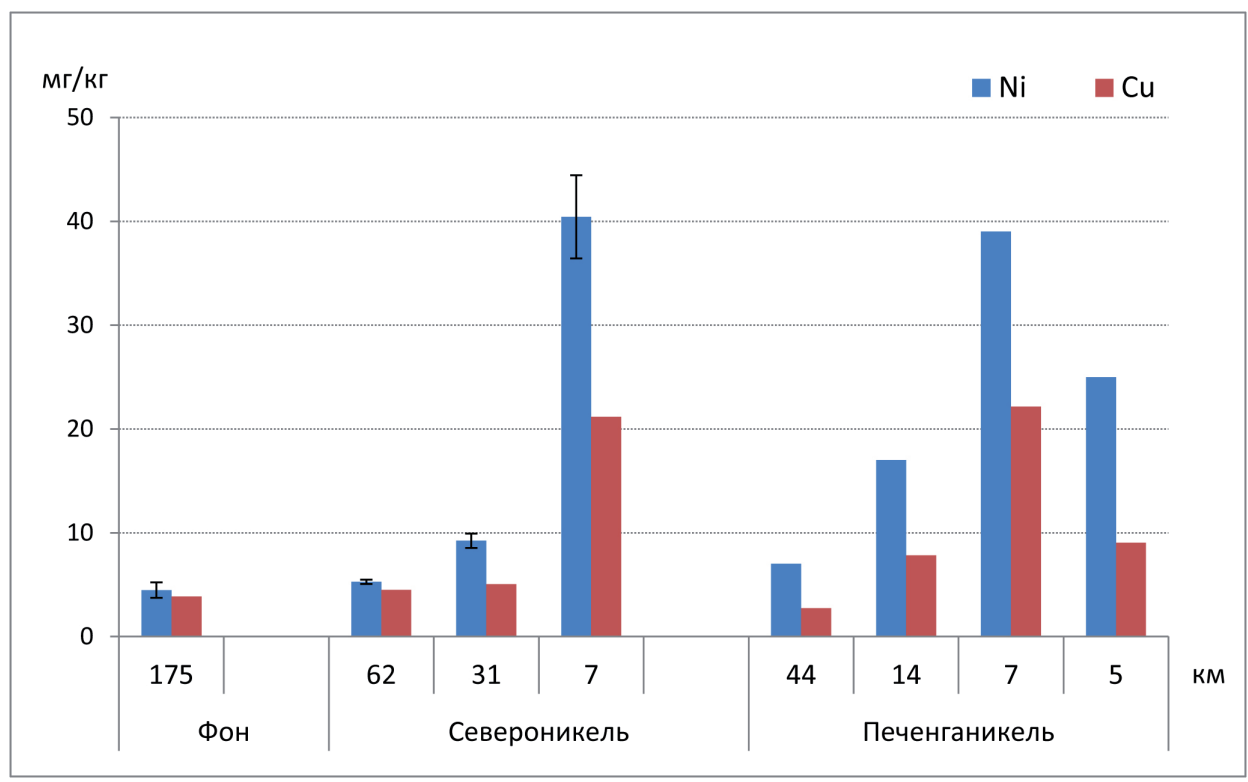

Рис. 1. Содержание $\mathrm{Ni}$ и Сu в луговике извилистом в зоне воздействия комбинатов «Североникель» и «Печенганикель» (межкроновое пространство), мг кг-1 абс. сух. в-ва, 2012 г.

тенсивно (рис. 1). Данная особенность в условиях атмосферного загрязнения отмечена и для других представителей биоты: хвойных и лиственных деревьев, кустарничков и лишайников $[2,7,9]$. Максимальная концентрация Fе отмечена на расстоянии 5-7 км от комбинатов. Выявлена положительная корреляционная связь между содержанием железа и никеля $(\mathrm{r}=0.88, \mathrm{p}<0.01, \mathrm{n}=31)$, железа и меди $(\mathrm{r}=-0.68, \mathrm{p}<0.01, \mathrm{n}=31)$. Отрицательные значения коэффициентов корреляции установлены между железом и кальцием $(\mathrm{r}=-0.38, \mathrm{p}<0.05, \mathrm{n}=31)$.

По градиенту атмосферного загрязнения от комбината «Североникель» увеличивается содержание кальция в луговике (табл. 1). В окрестностях комбината, где формируются техногенные редколесья, почвообразующие породы, содержащие габбро и габбронориты, обогащены основными катионами [4]. Благодаря этому бореальные растения в окрестностях комбината существенно не обедняются основными катионами и могут содержать даже повышенные по сравнению с фоном концентрации кальция. Содержание калия и фосфора в луговике на данной стадии дигрессии достоверно ниже фоновых показателей, что может быть обусловлено антагонистическим взаимодействием между элементами, что подтверждают рассчитанные коэффициенты корреляции: $\mathrm{Ca}-\mathrm{K}(\mathrm{r}=-0.55$, $\mathrm{p}<0.01, \mathrm{n}=31)$, Са-P ( $\mathrm{r}=-0.45, \mathrm{p}<0.01, \mathrm{n}=31)$. Напротив, между калием и фосфором выявлена тесная положительная корреляционная связь $(\mathrm{r}=0.81, \mathrm{p}<0.01, \mathrm{n}=31)$,

В зоне воздействия металлургических комбинатов в луговике достоверно $(\mathrm{p}<0.01)$ снижается концентрация марганца (табл.1). Наиболее значительно обедняются этим элементом растения техногенных редколесий: концентрация Mn в 2-4 раза ниже фоновых показателей. Одной из причин является критическое снижение содержание данного элемента в органогенном горизонте почв и одновременное обогащение почвы тяжелыми металлами на данной стадии сукцессии северотаежных лесов [8]. Кроме того, увеличение концентрации меди и никеля в луговике также приводит к снижению содержания марганца. Прослеживается отрицательная корреляционная связь между $\mathrm{Mn}-\mathrm{Ni}$ $(\mathrm{r}=-0.44, \mathrm{p}<0.01, \mathrm{n}=31), \mathrm{Mn}-\mathrm{Cu}(\mathrm{r}=-0.51, \mathrm{p}<0.01, \mathrm{n}=31)$.

Выявлены парцеллярные различия в элементном составе луговика, произрастающего в подкроновых и межкроновых пространствах. Значительное влияние на химический состав оказывают древесные растения (табл. 1, 2). Под кроной березы и сосны в луговике отмечены более высокие концентрация K, N, P ( $>$ >0.05). В березовой парцелле отмечено максимальное содержание перечисленных элементов. Под кроной сосны и березы возрастают концентрации тяжелых металлов - никеля и меди. Таким образом, дополнительным источником элементов минерального питания становятся элементы, вымываемые осадками из кроны деревьев. 
Таблица 1. Элементный состав луговика извилистого в зоне воздействия комбинатов «Североникель» и «Печенганикель» (в южном и юго-западном направлении от источника выбросов), 2012 г.

\begin{tabular}{|c|c|c|c|c|c|c|c|c|c|}
\hline $\begin{array}{l}\text { Расстояние от } \\
\text { комбината, км }\end{array}$ & $\begin{array}{l}\mathrm{K} \\
\Gamma / \mathrm{K} \Gamma\end{array}$ & $\begin{array}{l}\mathrm{N}, \\
\Gamma / \mathrm{K} \Gamma\end{array}$ & $\begin{array}{l}\mathrm{P} \\
\Gamma / \mathrm{K} \Gamma\end{array}$ & $\begin{array}{l}\mathrm{Ca}, \\
\text { Г/кГ }\end{array}$ & 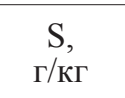 & $\begin{array}{l}\mathrm{Mg}, \\
\Gamma / \mathrm{K} \Gamma\end{array}$ & $\begin{array}{l}\mathrm{Mn}, \\
\Gamma / \kappa \Gamma\end{array}$ & $\begin{array}{l}\mathrm{Fe}, \\
\mathrm{M} / \mathrm{K} \Gamma\end{array}$ & $\begin{array}{c}\mathrm{Zn}, \\
\mathrm{M \Gamma} / \mathrm{K} \Gamma\end{array}$ \\
\hline $\begin{array}{c}175 \\
(260)^{*}\end{array}$ & $15.6 \pm 1.4$ & $12.4 \pm 0.4$ & $2.1 \pm 0.1$ & $1.5 \pm 0.1$ & $1.0 \pm 0.2$ & $0.8 \pm 0.1$ & $0.8 \pm 0.1$ & $37 \pm 2$ & $18 \pm 1$ \\
\hline & \multicolumn{9}{|c|}{ Комбинат « Североникель» еловые леса } \\
\hline 62 & $13.2 \pm 0.1$ & $9.4 \pm 0.4$ & $1.5 \pm 0.1$ & $1.7 \pm 0.2$ & $0.7 \pm 0.1$ & $0.6 \pm 0.0$ & $0.4 \pm 0.0$ & $36 \pm 2$ & $13 \pm 1$ \\
\hline $31 * *$ & $13.7 \pm 0.1$ & $11.4 \pm 1.1$ & $1.9 \pm 0.1$ & $2.3 \pm 0.2$ & $1.0 \pm 0.1$ & $0.7 \pm 0.0$ & $0.6 \pm 0.1$ & $44 \pm 2$ & $13 \pm 1$ \\
\hline \multirow[t]{2}{*}{7} & $10.7 \pm 0.1$ & $15.1 \pm 0.8$ & $1.1 \pm 0.1$ & $2.3 \pm 0.2$ & $1.7 \pm 0.2$ & $0.9 \pm 0.1$ & $0.2 \pm 0.0$ & $63 \pm 2$ & $23 \pm 1$ \\
\hline & \multicolumn{9}{|c|}{ Комбинат « Печенганикель» сосновые леса } \\
\hline 44 & $\frac{15.2}{16.5}$ & $\frac{13.7}{13.6}$ & $\frac{1.9}{1.7}$ & $\frac{1.3}{1.2}$ & $\frac{0.9}{1.1}$ & $\frac{0.9}{0.8}$ & $\frac{0.3}{0.4}$ & $\frac{33}{39}$ & $\frac{13}{15}$ \\
\hline 14 & $\frac{11.8}{16.9}$ & $\frac{9.9}{11.2}$ & $\frac{1.5}{1.6}$ & $\frac{1.3}{1.4}$ & $\frac{0.8}{1.0}$ & $\frac{0.8}{0.9}$ & $\frac{0.5}{0.7}$ & $\frac{53}{59}$ & $\frac{14}{17}$ \\
\hline 7 & $\frac{16.3}{19.0}$ & $\frac{11.4}{13.3}$ & $\frac{2.2}{2.4}$ & $\frac{1.3}{1.1}$ & $\frac{0.8}{0.9}$ & $\frac{0.8}{0.8}$ & $\frac{0.4}{0.4}$ & $\frac{111}{154}$ & $\frac{11}{15}$ \\
\hline 5 & $\frac{17.2}{21.3}$ & $\frac{11.7}{14.0}$ & $\frac{1.9}{2.4}$ & $\frac{1.2}{1.4}$ & $\frac{1.0}{1.0}$ & $\frac{0.9}{1.0}$ & $\frac{0.3}{0.4}$ & $\frac{51}{81}$ & $\frac{15}{22}$ \\
\hline
\end{tabular}

Примечание: здесь и в табл. 2 приведены средние значения ( \pm стандартная ошибка).

*_ фоновая территория, расстояние указано от медно-никелевых комбинатов «Североникель» («Печенганикель») **- Лапландский государственный природный биосферный заповедник.

над чертой - межкроновые пространства, под чертой - подкроновые (в остальных случаях данные только по межкроновым пространствам).

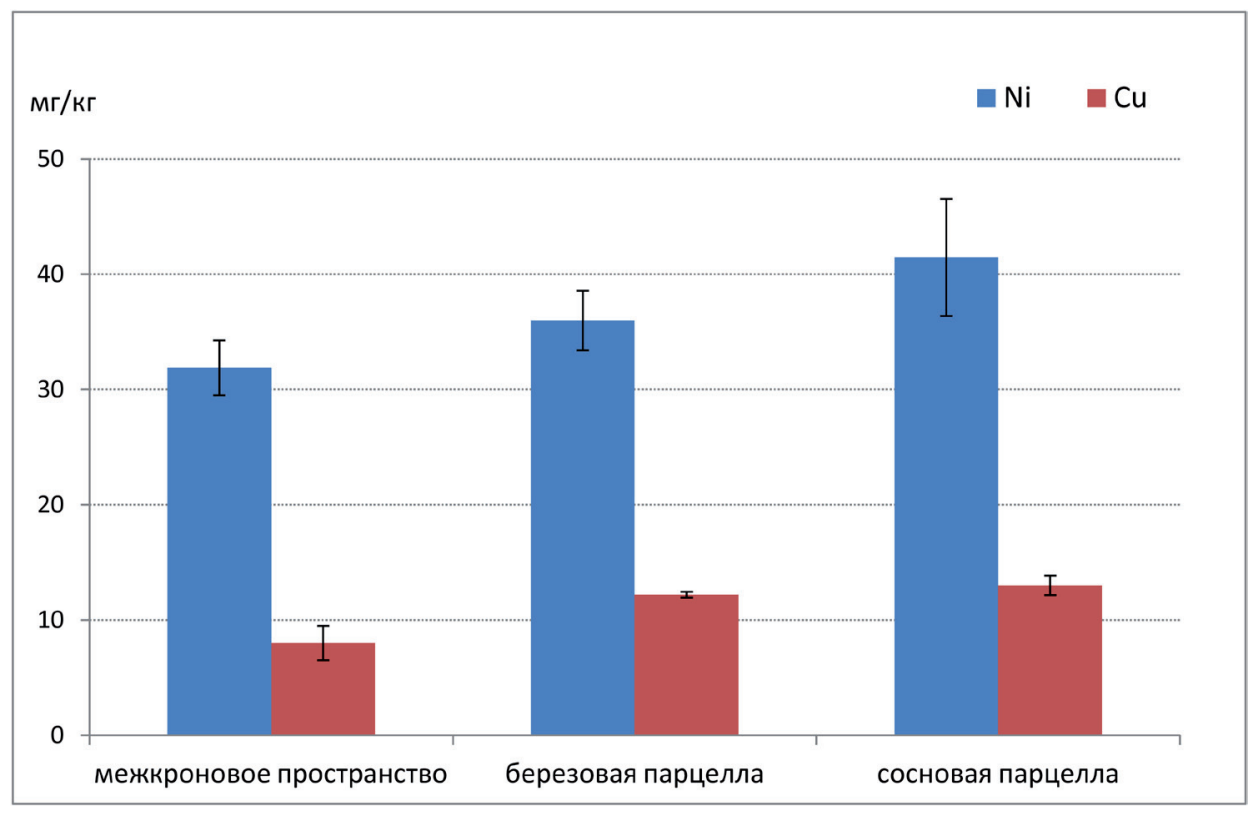

Рис. 2. Содержание $\mathrm{Ni}$ и $\mathrm{Cu}$ в луговике извилистом в зоне воздействия комбината «Печенганикель» (12 км в северном направлении от источника выбросов) в межкроновых и подкроновых пространствах, мг кГ-1 абс. сух. в-ва, 2013 г.

В результате проведенных исследований установлено, что трансформация химического состава луговика по сравнению с фоновыми значениями наблюдается на всех пробных площадях по градиенту загрязнения от металлургических комбинатов. Атмосферные выбросы плавильных цехов комбинатов «Североникель» и «Печенганикель» являются главным источником повышенных концентраций тяжелых металлов в луговике в процессе техногенной дигрессии северо-таежных лесов. Наибольшие концентрации $\mathrm{Ni}, \mathrm{Cu}, \mathrm{Fe}$ в луговике отмечены на расстоянии до 5-7 км от металлургиче- 
ских комбинатов, на стадии техногенных редколесий. Значительное влияние на химический состав луговика оказывают древесные растения. В подкроновых пространствах фитоценозов в луговике возрастает концентрация $\mathrm{K}, \mathrm{N}, \mathrm{P}, \mathrm{Fe}, \mathrm{Ni}, \mathrm{Cu}$. Почвенные условия и антагонистические отношения между элементами также определяют химический состав луговика на фоновых и техногенно нарушенных территориях.

Таблица 2. Элементный состав луговика извилистого сосновых лесов в зоне воздействия комбината «Печенганикель» (12 км в северном направлении от источника выбросов) в межкроновых и подкроновых пространствах, 2013 г.

\begin{tabular}{|c|c|c|c|c|c|c|c|c|c|}
\hline $\begin{array}{l}\text { Пространство } \\
\text { (парцелла) }\end{array}$ & $\mathrm{K}$, г/Кг & $\mathrm{N}$, г/кг & $\mathrm{P}$, г/кг & $\mathrm{Ca}$, г/кг & $\mathrm{S}$, г/кг & Mg, г/кг & Mn, Г/кг & $\mathrm{Fe}, \mathrm{мг} / \mathrm{к} Г$ & $\mathrm{Zn}, \mathrm{мг} / \mathrm{кг}$ \\
\hline межкроновое & $12.0 \pm 1.2$ & $4.2 \pm 0.1$ & $1.5 \pm 0.1$ & $1.5 \pm 0.1$ & $1.5 \pm 0.0$ & $0.7 \pm 0.0$ & $0.6 \pm 0.0$ & $85 \pm 3$ & $11 \pm 1$ \\
\hline $\begin{array}{l}\text { подкроновое } \\
\text { (сосновая) }\end{array}$ & $15.0 \pm 1.3$ & $4.7 \pm 0.3$ & $1.7 \pm 0.1$ & $1.4 \pm 0.1$ & $1.5 \pm 0.0$ & $0.8 \pm 0.0$ & $0.5 \pm 0.1$ & $116 \pm 3$ & $13 \pm 1$ \\
\hline $\begin{array}{l}\text { подкроновое } \\
\text { (березовая) }\end{array}$ & $16.0 \pm 0.9$ & $5.7 \pm 0.4$ & $2.0 \pm 0.1$ & $1.2 \pm 0.1$ & $1.5 \pm 0.0$ & $0.7 \pm 0.0$ & $0.5 \pm 0.1$ & $104 \pm 11$ & $15 \pm 1$ \\
\hline
\end{tabular}

\section{Литература}

1. Жукова Л. А. Биологическая флора Московской области. Вып. 5. 1980. Изд-во Московского университета. С. 46-57.

2. Исаева Л.Г., Сухарева Т.А. Элементный состав дикорастущих кустарничков в зоне воздействия комбината «Североникель»: данные многолетнего мониторинга // Цветные металлы. 2013. № 10. С. 86-92.

3. Л Лирин И.В. Кормовые растения сенокосов и пастбищ СССР. Т. 1-2. М.-Л.: Сельхозгиз.

4. Лукина Н.В., Никонов В.В. Питательный режим лесов северной тайги: природные и техногенные аспекты. Апатиты. Изд-во КНЦ РАН. 1998. 316 с.

5. Никонов В.В., Лукина Н.В. Биогеохимические функции лесов на северном пределе распространения. Апатиты. Изд-во КНЦ РАН. 1994. 315 с.

6. Рассеянные элементы в бореальных лесах / Отв. ред. А.С. Исаев. М.: Наука. 2004. 616 с.

7. Сухарева Т.А. Элементный состав листьев древесных растений в условиях техногенного загрязнения // Химия в интересах устойчивого развития. 2012. № 3. С.369-376.

8. Сухарева Т.А. Пространственно-временная динамика микроэлементного состава хвойных деревьев и почвы в условиях промышленного загрязнения // Изв. высших учебных заведений. Лесной журнал. № 6. 2013. C. 19-28.

9. Сухарева Т.А. Элементный состав талломов лишайника Cladonia stellaris в условиях атмосферного загрязнения // Тр. КарНЦ РАН. 2016. №4. С. 70-82.

10. Sciirfield G. Biological flora of British Isles: Deschampsia flexuosa (L.) Trin. -Journ. Ecol. V. 42. № 1. 